\title{
Contribution to ECDIS Reliability using Markov Model
}

\author{
Dean Sumića, Dragan Perakovićb, Marinko Jurčevićb
}

An Integrated Bridge System (IBS) contains a fully duplicated Electronic Chart Display and Information System (ECDIS). Although duplication should increase system reliability, reliability and availability are not improved. Proper ECDIS maintenance includes updating both: the information system and the provided chart system. This procedure, in practice, tends to decrease reliability and availability. A Markov ECDIS simulation model is given. A new design concept is presented and proposed. The entire ECDIS system is improved by adding a cold standby system preventing the occurrence of errors due to updating and upgrading of the system device.

\section{KEY WORDS}

$\sim$ Markov model

$\sim$ ECDIS

$\sim$ IBS

$\sim$ Reliability

$\sim$ Cold standby

\footnotetext{
a. University of Split, Faculty of Maritime Studies, Split, Croatia

e-mail: suma@pfst.hr
}

b. University of Zagreb, Faculty of Transport and Traffic Sciences, Zagreb, Croatia e-mail: dragan.perakovic@fpz.hr

\section{INTRODUCTION}

The International Maritime Organization (IMO) adopted the International Convention of the Safety of Life at Sea (SOLAS), together with the amendments to SOLAS Chapter V Regulation 19 governing the statutory introduction of ECDIS (SOLAS; International Association of Marine Aids to Navigation and Lighthouse Authorities, 2004). The amendments to SOLAS Chapter V Regulation 19 -Carriage Requirements for Shipborne Navigational Systems and Equipment came into effect on 1 January 2011.

As of 1 July 2012 onboard mandatory implementation of ECDIS as the primary navigation system for different ship types and sizes came into force. This means that oceangoing ships are required to have ECDIS equipment. Whenever a new device or system are installed onboard a ship certain activities are required to be taken by appropriate administration, shipper and crew. Several years of its implementation confirmed ECDIS contribution to ship safety and efficient navigation. The ECDIS subsystem is a part of the IBS and a benchmark in navigation management compared to former methods. Due to the importance of ECDIS for safety and the fact that is not merely a matter of installation of new hardware only to meet a statutory requirement, this paper analyses and proposes its own contribution to successful implementation and use of the ECDIS.

IMO's Sub-committee on Safety of Navigation, Communication, Search and Rescue held its first session in London 30 June - 4 July 2014. The new sub-committee is a merger of the NAV Sub-committee on Safety of Navigation and the COMSAR Sub-committee on Communication and Search and Rescue (IMO, 2014). 


\section{INTEGRATED BRIDGE SYSTEMS}

During its design and construction, every merchant fleet ship must meet all IMO, classification society and flag state requirements and regulations. This includes ship's Computer Based Systems (CBS) and Integrated Bridge Systems (IBS) which operate extremely complex marine applications. They provide advanced navigation capabilities and improve ship safety. These systems should ensure that the crew is made aware of failure of any subsystem by audible and visual alarms, and that the failure does not cause failure to any other subsystem. SOLAS stipulates that in the event of failure of a part of an integrated navigation system, all other individual items of equipment or system parts must be able to function independently (SOLAS).

An integrated bridge system (IBS) is defined as a combination of systems interconnected in order to allow centralized access to sensor information or command/control from workstations, to increase the safety and efficiency of ship management by suitably qualified personnel. Performance standards for integrated bridge systems were adopted by IMO in 1996 as Maritime Safety Committee (MSC) Resolution MSC.64 (67).

An example of an IBS system is analyzed in Figure 1. Integrated Navigation System (INS) is the latest generation of IBS, approved in keeping with IMO's new INS performance standards MSC.252(83). It combines a plethora of individual navigation components into one seamlessly developed navigation and bridge system. The modern INSs not only fulfill basic IMO requirements but exceed them. The use of standard hardware and software allows the configuration of modular system solutions as illustrated in Figure 1. The proposed system and its components should, apart from IMO, also meet other relevant standards of International Hydrographic Office (IHO) and International Electrotechnical Commission (IEC).

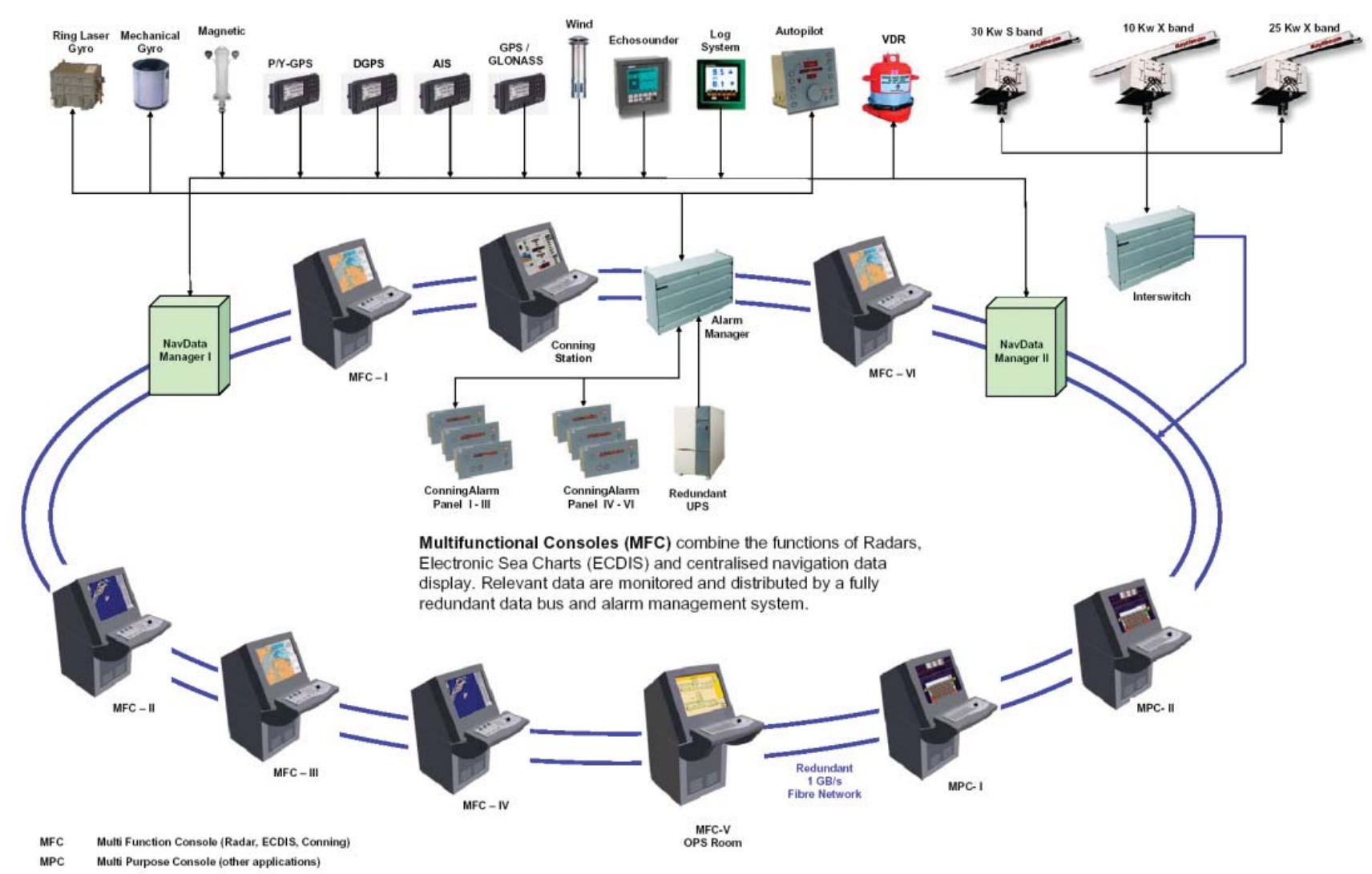

Figure 1.

Raytheon Anschütz's Synapsis Integrated Bridge System. Source:Integrated Navigation - Synapsis Bridge Control, (2014). 
INS incorporates the ECDIS solution as one of its most relevant subsystems. Figure 1 illustrates the integration of the ECDIS subsystem into a Multi Function Console (MFC). Reliable high-performance sensors (such as gyro compass, echo sounder, speed log, DGPS and weather sensors) provide all data required by the system, which are distributed and monitored by fully redundant data - and alarm management through $1 \mathrm{~GB} / \mathrm{s}$ fiber local area network (LAN).

Typical IBS/INS characteristics:

- Route monitoring,

- Autopilot operation integrated into radar and ECDIS,

- Central alarm management with integrated monitoring by watch officer,

- Alarm system alerting the captain / alert transmitted in the living quarters,

- Overlay of radar/ECDIS/AIS representations,

- Central presentation of navigation data (conning),

- Display of conning data on the ECDIS,

- Evaluation of remaining system performance and

- Remote diagnostics.

In spite of the greater quantity of technology and mandatory installation of equipment like ECDIS, the total number of navigational accidents of seagoing vessels is increasing according to (Nicholson, 2013).

For this negative trend to be reversed, the present interaction of the CBS and the crew operating the equipment must be analyzed and itself be made apart of the Systems of Systems (SoS). Bridge crew has to monitor and instruct the CBS. As bridge crew become accustomed to system operation, their reliance on the system grows and the actions of the crew adjust to the perceived equipment capabilities (Nicholson, 2013).

\section{ECDIS}

ECDIS is represented by means of a software system used to display nautical charts, voyage watch and voyage planning. ECDIS is defined in the IMO ECDIS Performance Standards, IMO Resolution A.817 (19), as follows:

Electronic Chart Display and Information System (ECDIS) means a navigation information system which, with adequate back up arrangements, can be accepted as complying with the up-to-date chart required by regulation V/19 \& V/27 of the 1974 SOLAS Convention, by displaying selected information from a system electronic navigational chart (SENC) with positional information from navigation sensors to assist the mariner in route planning and route monitoring, and by displaying additional navigation-related information if required.

In addition to IHO/IMO compliant vector electronic navigation charts (ENC), ECDIS also displays raster charts (ARCS). Since raster charts are produced by scanning paper charts, they do not consist of database-based active alarms, and are not to be analyzed in this paper.

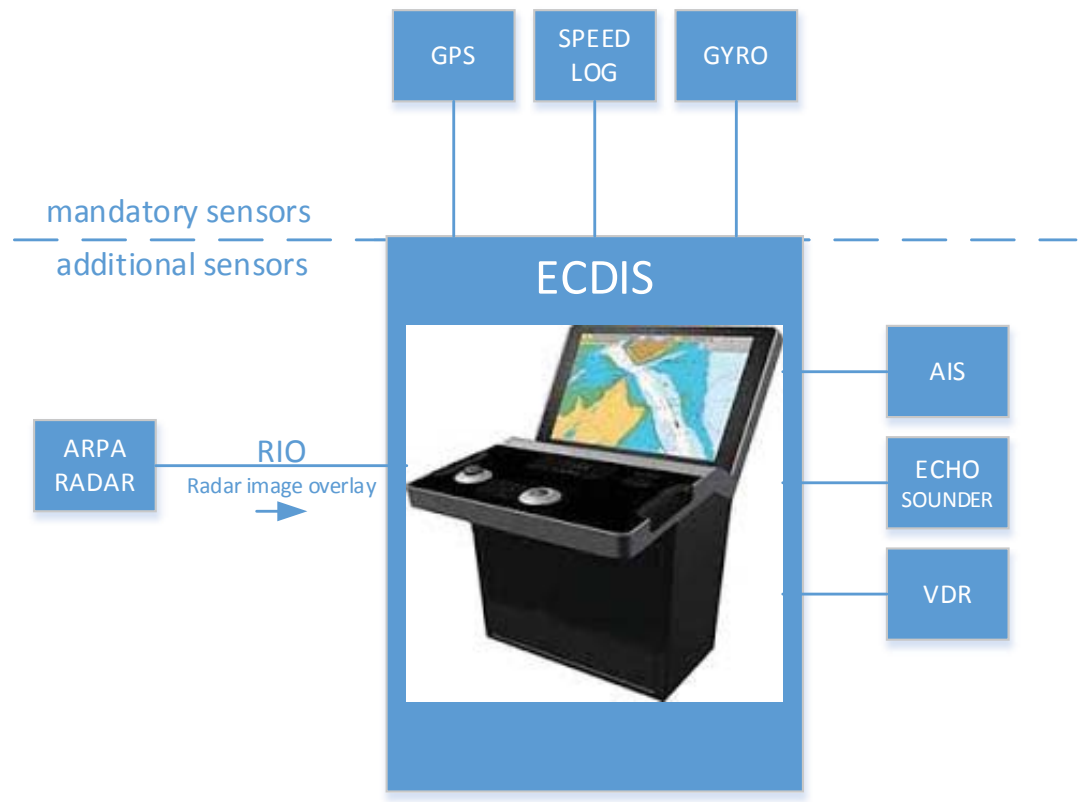

Figure 2.

ECDIS sensors plan. 
ECDIS is connected to various subsystems and sensors as shown in Figure 2.

According to IMO performance standards, the ECDIS should be connected to ship's systems providing continuous position, heading and speed information. The ECDIS can also be connected to non-mandatory, additional sensors as illustrated in Figure 2. Mariners should not rely solely on GPS positioning when there are alternative positioning facilities available. GPS is subject to a variety of different errors.

ECDIS consists of three elements: hardware, software and database. ECDIS is the most complex, most sophisticated and most expensive marine navigation system. An ECDIS is capable of displaying all chart information necessary for safe and efficient navigation. It displays the ship's position, as well as the positions of other ships. The implementation of an onboard system of ECDIS's complexity implies the existence of a procedure in the Safety Management System (SMS) to be applied in the event of sensory input failure to ECDIS. As a vital part of SMS onboard implementation, a checklist should be put up on the bridge containing clear instructions on how to deal with sensory input failures and what effect they might have on ship's navigational safety.

Onboard system can be realized with standalone ECDIS. It can also be conceived as dual configuration, or be integrated into INS/IBS as part of MFC.

Electronic navigation systems cannot be guaranteed to be $100 \%$ failsafe; with this in mind, there must be some form of back-up or redundancy in case of ECDIS failure. IMO performance standards require the 'overall system' to include both a primary ECDIS and an adequate, independent back-up arrangement to ensure the safe take over of ECDIS functions without causing a critical situation. The independent back-up arrangement must ensure safe navigation of the ship for the remaining part of the voyage in case of ECDIS failure.

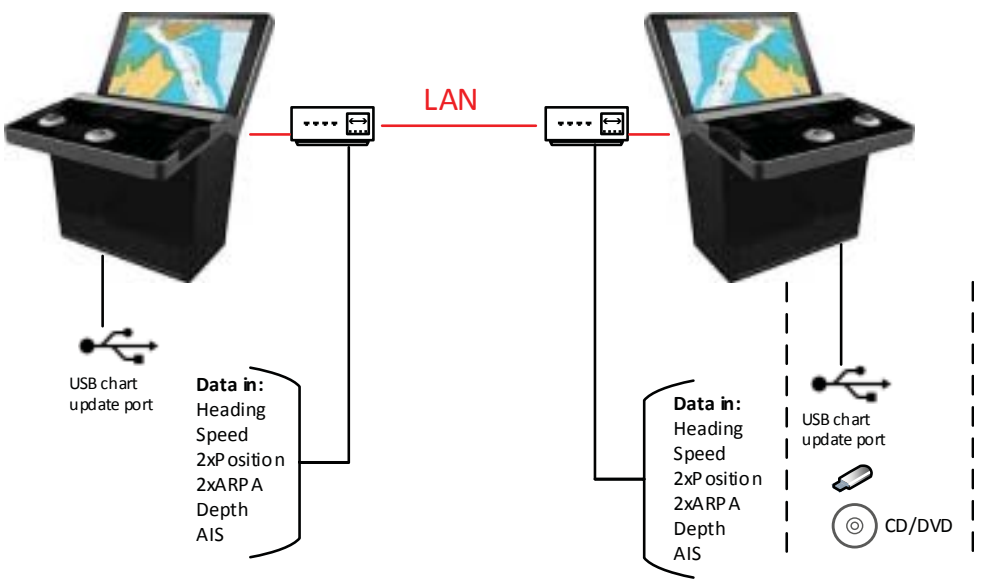

Figure 3.

Dual ECDIS configuration.

Source: Integrated Navigation - Synapsis Bridge Control, 2014

ECDIS operators must ensure that their software always conforms to the latest $\mathrm{IHO}$ standards and that an officially recognized distributor/service provider delivers regular service updates on software and official ENC/RNC data.

All masters and navigation officers should know how to update and maintain their onboard ECDIS. It should not be left to the designated navigation officer to have sole knowledge on the updating procedure and process. Updating procedures should be covered under ECDIS generic training but, more importantly, under type specific training as well, since different ECDIS models vary in their updating processes.

Keeping the ECDIS fully up to date should be made high priority for the bridge team and treated as equally important as normal paper chart corrections. ECDIS updates normally coincide with weekly paper chart corrections. Updates can be sent via e-mail and transferred onto CD or USB flash drive for ECDIS needs. Any device used to transfer ECDIS updates should be a dedicated unit for that sole purpose and be free of any viruses that may corrupt ECDIS software. Software and extensive ENC/RNC updates are generally received on a data CD/DVD and delivered to the ship by a human agent on a weekly basis, particularly when files are too large or expensive to be sent by e-mail. ECDIS should store and display an updates record on demand, including the time of application of the ECDIS database, known as system electronic navigational chart (SENC). This record should include updates for each ENC until it is superseded by a new version. In order for the ECDIS to fully comply with IMO performance standards and display all relevant digital 
information contained within an ENC, it should be updated to the latest version of the ENC product specification. Additionally, any ECDIS that is not updated to S-63 Data Protection Standard may fail to decrypt or properly authenticate the ENC. When failure to update ECDIS properly occurs, it may result in the latest charted features not being displayed or failure of alarms/indications even if new charted features have been included in the ENC. An ECDIS that is not updated correctly and on a regular basis may not meet the chart carriage requirements as set out in SOLAS regulation V/19.2.1.4. Therefore, IMO published a Safety of Navigation Circular 266 'Maintenance of ECDIS software'.

Although ECDIS equipment and ENCs are designed to maintain a high level of reliability, there is a slightly increased risk of occurrence of problems when adding, removing or updating ENCs. Changes to installations AVCS ENCs when the equipment isused only for navigation or if the ship is about to leave port are not permitted. In (Admiralty Vector Chart Service Installation Guide, 2010) it is stated that every ECDIS update is potentially dangerous for ship safety.

In ships using ECDIS as their primary mean of navigation (no paper charts), an additional and independent ECDIS as a back-up option is generally accepted and meets SOLAS carriage requirements. The back-up ECDIS should be connected to an independent power supply and systems with continuous positioning capability.

When the ECDIS is being operated in Raster Chart Display System (RCDS) mode using RNC data due to the lack of suitable coverage by electronic navigational charts (ENC), an appropriate folio of up-to-date paper charts must be maintained for areas where only raster chart coverage is available.

\section{AVAILABILITY CALCULATING MODEL}

To obtain a mathematical reliability calculating model, some basic definitions must be known.

\subsection{Reliability}

The general concept of reliability is related to the qualitative properties of something/someone that is there, in the sense that something/someone is predictable and available when needed. Reliability can be defined as follows:

Reliability $R(t)$ is the probability of performing a specific function under given conditions for a specified period of time without failure (O'Connor and Kleyner, 2012; Skomeršić, 2010; Specht, 2003).

Reliability function is a survival function designated as $R(t)$. $R(t)$ is the probability that the considered item (device, system, etc.) will operate failure - free in $[0, t]$ shown in (1). It is worth observing that the reliability function, being a probability, is dimensionless.
$1 \geq R(t) \geq 0$

where:

$\mathrm{R}(0)=1$ and $\mathrm{R}(\infty)=0$.

Reliability can be expressed with failure rate $a(t)$ as an initial condition when reliability at time 0 is at a maximum and equal to 1 ; then we have (2):

$R(t)=e^{-\int_{0}^{t} \lambda(t) d t}$

Mean Time To Failure (MTTF) can express expected time between failures.

MTTF $=\int_{0}^{\infty} t \cdot\left(-\frac{d}{d t} R(t)\right) d t$

Common case is $\lambda(t)=\lambda_{0}$ equals to constant and then (2) becomes (4) and relation (3) becomes (5) (Lazzaroni et al., 2011).

$R(t)=e^{-\lambda 0^{\circ} t}$

$M M T F=\frac{1}{\lambda_{0}}$

\subsection{Availability}

Availability is defined in (Lazzaroni et al., 2011) as "the aptitude of the element to perform its required function in given conditions up to a given point in time or during a given time interval assuming that any eventual external resource is assured."

The availability of a machine can also be defined as the percentage of time, in respect to total time, over which that machine is required to function.

Availability $A(t)$ can be defined as"the ability of an item to be in a state to perform a required function under given conditions at a given instant of time or over a given time interval, assuming that the required external resources are provided (Ebeling, 2014; Skomeršić, 2010).

Availability is defined as the probability that an item will be available when required, or as the proportion of total time that an item is available for use (O'Connor, 2012). Availability can be expressed as (6) (Nakagawa, 2005). Limiting interval availability is the anticipated fraction of time over which a system will operate, which is given by

$A=\lim \left\{\frac{T_{\text {uptime }}}{T_{0}}\right\}$ 
This quality system parameter requires the reduction of system downtime to the minimum. Therefore the availability of a repairable item is a function of its failure rate, $\lambda$, and its repair or replacement rate $-\mu$.

$$
A(t)=\frac{\mu}{\lambda+\mu}
$$

\subsection{Modeling}

The dynamic modeling in the ITS environment requires the actual values of traffic variables to be known and operation in real time.

The studying of various maintenance policies is important in order to prevent the occurrence of system failures in the field and improve system availability. System availability can either be calculated by modeling the system as an interconnection of parts in series and in parallel, or by means of measuring the methods of an actual system. Both approaches require excellent knowledge of the system analyzed. For practical reasons, availability is often estimated based on an ideal model. On the other side, precise on-site measurements provide exact data, but are more laborintensive and require significant resources (time, higher costs, dedicated onboard equipment, etc.)

Redundant IMO-compliant ECDIS for navigation, consisting of two identical devices can be modeled by means of two parallel identical system elements as shown in Figure 4.

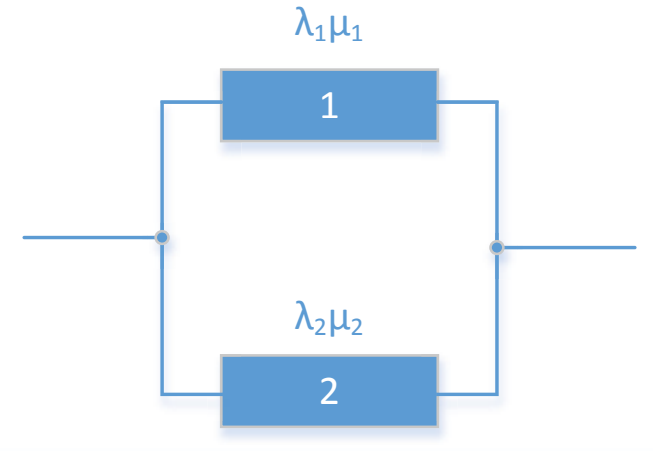

Figure 4.

Dual Redundant ECDIS model.

When Markov analysis is used, a two-component system can be in one of the four possible states as presented in Table 1. Any $n$ component can have two possible states: working or failed. System states are defined as one of $2 \mathrm{n}$ possible combinations.
Table 1.

Possible system states.

\begin{tabular}{lll} 
State & Component $\mathbf{1}$ & Component $\mathbf{2}$ \\
\hline 1 & Working & Working \\
\hline 2 & Failed & Working \\
\hline 3 & Working & Failed \\
\hline 4 & Failed & Failed \\
\hline
\end{tabular}

For a parallel system, the system's failed or "down" state is S4. The corresponding system's "up" states are respectively [S1, S2, S3]. System reliability is defined as the probability of being "up", i.e. not being in a failed state. The aim is to calculate the probability of occurrence of each state (Lazzaroni et al., 2011).

$R_{p}(t)=P_{1}(t)+P_{2}(t)+P_{3}(t)$

Since the system must be in one of the four possible states at any given moment, we get:

$P_{1}(t)+P_{2}(t)+P_{3}(t)+P_{4}(t)=1$

where calculation of probabilities is needed: $P_{i}(t)$ for $i=1,2,3,4$.

Markov processes can be used to represent a system in which events take place according to specified probabilities. When a system can be modeled by taking into account all possible states the model is exposed to, it is advisable to make a Markov model. A stochastic model is a process in which the state depends on the previous states in a non-deterministic way. A stochastic process has Markov properties if the conditional probability distribution of future states of the process (conditional on both past and present values) depends solely upon the present state; that is, given the present, the future does not depend on the past. Markov processes are distinguished by being memoryless - their next state depends only on their current state, not on the history that led them there. Markov analysis provides a framework in which to study the behavior and emergent properties of these systems. To analyze system events as a Markov process, the system should transit from one state to another, and these transitions should occur in keeping with transition probabilities. This model allows the identification of long term behavior of the status of these systems. The consistent behavior of states of these systems is of great value to an analyst planning or budgeting resources or projecting costs or profit in systems in which events take place in an environment of uncertainty (Carter and Price, 2001). 


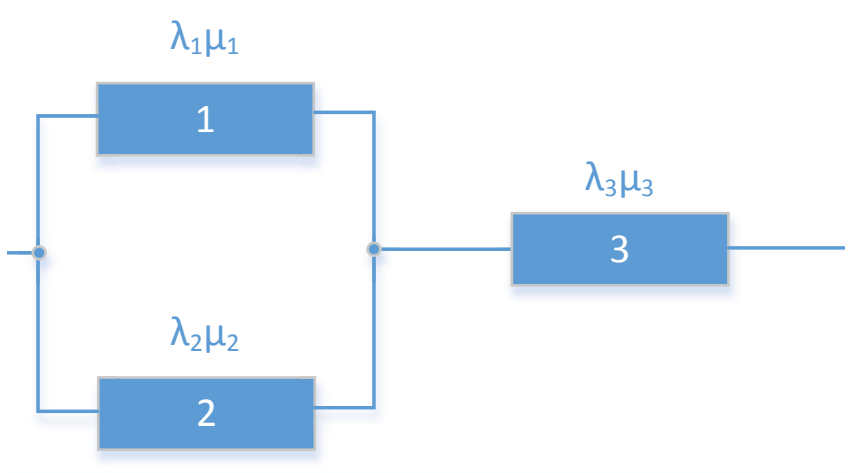

Figure 5.

Enhanced ECDIS model with update..

IMO regulations require a mandatory redundant system. This requires the modification of the model from Figure 4. Updating is common to both, elements $1 \& 2$, and must be taken into account when modeling. A new mathematical model, which also takes into account the updating process, is illustrated in Figure 5. The serial element of the parallel redundant model must be considered. The updating process involved is represented by serial element 3. This serial element compromises the achieved ECDIS reliability, in spite of IMO's intention behind the redundant system requirement.

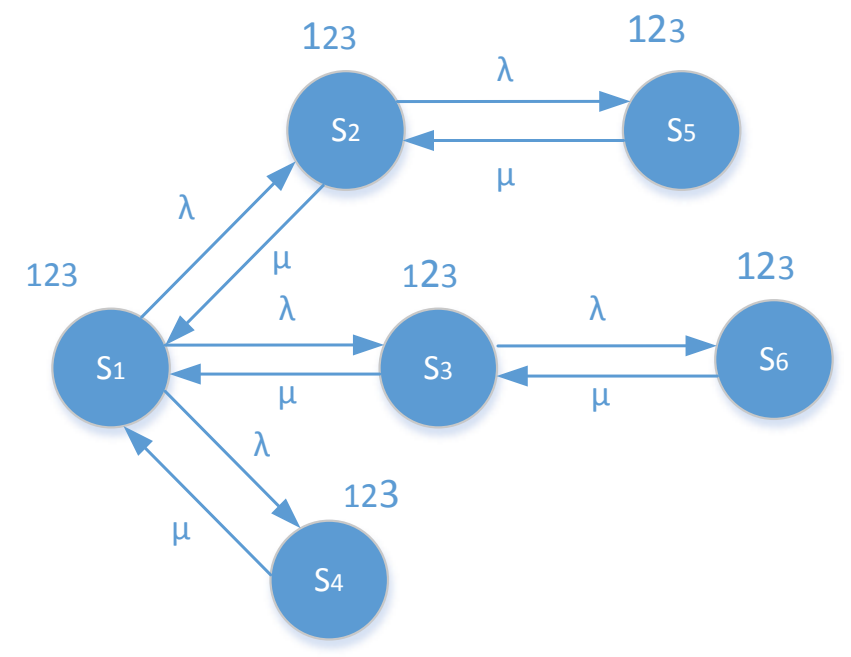

Figure 6.

Markov model structure.

According to model shown in Figure 5, Markov model proposed is shown in Figure 6. That model can be transformed into a simplified form shown in Figure 7.

If $\lambda$ and $\mu$ coefficients are known, system reliability can be calculated. The calculation of a system's working state probability will show that the desired level of reliability is not achieved. A truly reliable, highly available overall ECDIS system is a must for truly paperless charting.

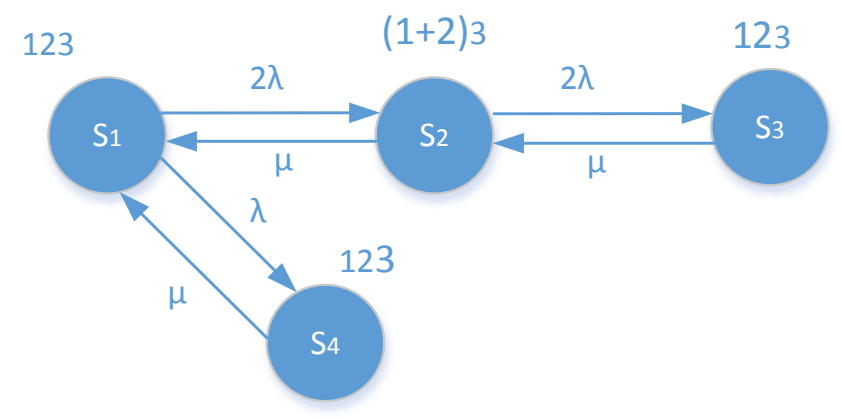

Figure 7.

Concise Markov model structure.

\section{PROPOSAL FOR TECHNICAL SOLUTION}

The analysis of models described in the previous chapter shows that the serial element degrades system availability and reliability. Adding a new element would not significantly increase availability. The same third parallel element added to the system would suffer from dependency on the serial element as well. Increasing the number of parallel elements increases overall system costs.

To increase overall system availability technical solution from Figure 8 is proposed, under the assumption that the existing, IMO mandatory ECDIS is capable of being upgraded to the new concept. This could be realized by means of cold standby device implementation. The cold standby system would be a real benchmark in maritime safety since existing mandatory reliability still needs backup in the form of paper charts in case of ECDIS malfunction (Admiralty Vector Chart Service Installation Guide, 2010).

The alternative to the proposed solution are paper charts. It is much more convenient for ship safety to obtain an alternative ECDIS from another device and ENC manufacturer than to rely, in case of a system malfunction, on paper charts. Paper charts are, even if available, not updated by the crew.

The additional ECDIS solution also needs to be updated, but overall system errors, which caused the malfunction, could be avoided if ECDIS and ENC came from different manufacturers. This can be accomplished by installing the equipment of totally different manufacturers of hardware with the ECDIS application and ENCs. This solution implemented onboard as a new backup option could make paper charts redundant. In Figure 8, primary redundant system runs AVCS ENCs on Raytheon ECDIS equipment, and cold standby system runs on Primar ENCs with Kongsberg ECDIS equipment is shown. 


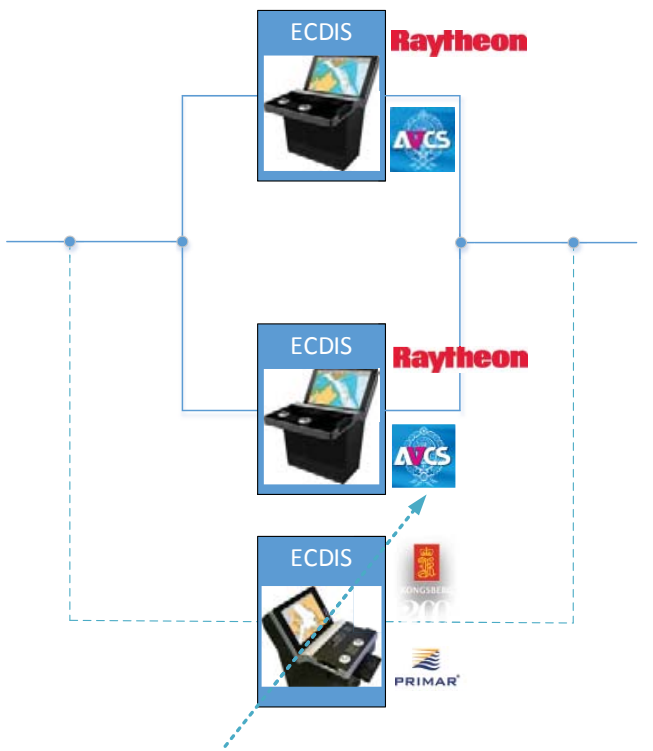

Figure 8.

ECDIS concept solution.

The overall cost of the proposed solution could be analyzed from the point of view of an emergency. This means that in case of emergency a cold standby system running on IBS/INS could be updated by means of temporary permit license keys that wouldn't be charged at commercial prices.

The proposed cold standby system shown in Figure 8 would improve maritime safety.

\section{CONCLUSIONS}

Modern e-navigation is a set of integrated technologies in IBS/INS. The navigator's mission is to safely pilot the ship across the desired route. ECDIS devices historically developed from devices facilitating navigation to mandatory devices used as primary, vital means of navigation.

Two redundant ECDISs are IMO mandatory devices implemented as subsystems of the IBS/INS design. IMO's assumption was that duplicating device equipment would increase overall system reliability. Equipment duplication does not double the reliability and availability of mandatory equipment.

Emergency backup usage of obsolete paper charts significantly decreases high levels of accomplished maritime safety.

The calculation of reliability of an existing, mandatory system, with known coefficients, gives unsatisfactory results. The calculation of reliability of the proposed system, based on the Markov model, with known coefficients, gives satisfactory results.
The proposed model of a cold standby device system would ensure higher level of maritime safety in case of malfunction of an active redundant system than paper charts. The use of a third ECDIS device produced by a different manufacturer, either device or chart system, would significantly improve maritime safety. IBS/ INS safety function role would not be compromised.

\section{REFERENCES}

Admiralty Vector Chart Service Installation Guide,(2010), London, available at: http://www.ukho.gov.uk/ProductsandServices/ElectronicCharts/Pages/AVCS.aspx, [accessed 23 June 2014.].

Bošnjak, I. and Badanjak, D., (2005), Osnove prometnog inženjerstva, Zagreb: Fakultet prometnih znanosti.

Carter, M. W. and Price, C. C., (2001), Operations Research: A Practical Introduction, Boca Raton, FI, USA: CRC Press LCC.

Circular letter 33/2012, (2012), International Hydrographic Organization, Monaco, available at: http://www.iho.int/mtg_docs/circular_letters/english/2012/Cl33e.pdf, [accessed 23 May 2014.].

Ebeling, C. E., (2014), An Introduction to Reliability and Maintainability Engineering, Long Grove, Illinois: Waveland Press Inc.

Grover, W. D., (2003), Mesh-based Survivable Transport Networks, Upper Saddle River, NJ: Prentice Hall PTR.

Human Element, (2014), International Maritime Organization (IMO), available at: http://www.imo.org/OurWork/HumanElement/Pages/Default.aspx, [accessed 3 September 2014.].

Integrated Navigation - Synapsis Bridge Control, (2014), Raytheon Anschütz GmbH, available at: http://www.raytheon-anschuetz.com/commercial-systems/integratednavigation/, [accessed 29 -June 2014.]

International Association of Marine Aids to Navigation and Lighthouse Authorities, (2004), Guide to the Availability and Reliability of Aids to Navigation - Theory and Examples, Saint Germain en Laye, France: IALA, available at: http://www. industrycortex.com/datasheets/profile/501828799/international-association-ofmarine-aids-to-navigation-and-lighthouse-authorities-iala-guideline-no.-1035-to, [accesses 1 July 2014.].

International Hydrographic Organization, (2014), available at: http://www.iho.int. [accessed 10 February 2014.]

International Maritime Organization, (2014), available at: http://www.imo.org/ Pages/home.aspx, [accessed 4 July 2014.].

Lazzaroni, M., Cristaldi, L., Peretto, L., Rinaldi, P. and Catelani, M., (2011), Reliability Engineering, Basic Concepts and Applications in ICT, Berlin Heidelberg: SpringerVerlag.

Nakagawa, T., (2005), Maintenance Theory of Reliability, London: Springer-Verlag.

Nicholson, M., (2013), Computer Safety For Modern Bridge Systems, Journal of Navigation, 66(5), pp. 789-797.,

http://dx.doi.org/10.1017/S0373463313000180

O'Connor, P. and Kleyner, A., (2012), Practical Reliability Engineering, fifth edition, West Sussex: John Wiley \& Sons.

Skomeršić, M., (2010), Raspoloživost VoIP sustava s kraja na kraj u mrežama nove generacije, Kvalifikacijski doktorski ispit, (in Croatian), University of Zagreb, Faculty of Electrical Engineering and Computing, available at: http://crv.fer.hr/_download/ repository/Marko_Skomersic_KDI.pdf, [accessed 11 June 2014.]. 
Specht, C., (2003), Availability Reliability and Continuity Model of Differential GPS Transmission, Annual of Navigation, 5(2003), 85 p., available at: http://yadda. icm.edu.pl/baztech/download/import/contents/BAT3-0024-0108-httpwww_ annualofnavigation_plannualspechthab1206291401018884.pdf, [accessed 12 May 2014.].

Spencer, C. and Tilsley, D., (2011), ECDIS - UNDERSTANDING THE FUTURE OF NAVIGATION SPECIAL EDITION, The Standard Safety Club, pp. 1-16, available at: http://standard-club.com/media/23812/StandardSafetyECDIS24August2011.pdf, [accessed 12 June 2014.].
International Hydrographic Organization, (2014), available at: http://www.iho.int. [accessed 10 February 2014.].

SOLAS (Safety of Life at Sea) Consolidated Edition, (2014), International Maritime Organization., available at:

http://www.imo.org/Publications/Documents/Attachments/IF110E.pdf 